\title{
Some challenges on the aeroelastic analysis and design of long span bridges
}

\author{
S. Hernandez, F. Nieto, A. Baldomir \& J. A. Jurado \\ School of Civil Engineering, University of Coruña, Campus de Elviña, \\ A Coruña, Spain
}

\begin{abstract}
Many suspension or cable stayed bridges of very long span length have been built in the past decades and several projects of similar or even greater significance are under study. One of the main requirements of these structures is their safety under high wind speeds. Bridge aeroelasticity is the scientific field that study such a problem and is nowadays a quite well established discipline but some challenges, such as the proper procedure for the evaluation of wind speed, the use of CFD techniques or design optimization methodologies remain to be solved. This paper explains the current situation of these topics and outlines some ways out to be considered.
\end{abstract}

Keywords: long span bridges, bridge aeroelasticity, reliability analysis, computational fluid dynamic, structural optimization.

\section{Introduction}

The number of long bridges built in the last decades is really very significant and examples of these structures can be found in each continent, for instance the Great Belt and the Oresund bridges in Denmark, the Stonecutters and Tsing Ma bridges in Hong Kong, the Tatara and Akashi bridges in Japan or the Sutong and Xihoumen bridges in China are cases of recent realizations and the future bridge over the Forth river (UK), the Messina strait (Italy), the Chacao channel (Chile), or the era2000 project (Spain) [1] represent future links under development.

All these structures need a complete study to identify their behaviour under wind loads, in other words, to check their aeroelastic behaviour. In that regards it can be accepted that bridge aeroelasticity is nowadays a well established discipline. Tests carried out in boundary layer wind tunnel with reduced models 
of the full bridge produce realistic results of practical use in real projects. Also tests of segmental models of bridge deck aimed to identify the set of the so called flutter derivatives defined by Scanlan are very useful as they can afterwards be used to obtain the flutter speed of a bridge by formulating the dynamic equilibrium of bridge under aeroelastic forces.

Nevertheless, some improvements in the methodologies used currently by introducing more accurate approaches already used in other engineering fields, should be incorporated in aeroelastic studies of long span bridges.

Also some unsolved problems remain ahead and researchers of this topic may be confident that a lot of work has to be done in the forthcoming years to succeed over these challenges.

In the forthcoming paragraphs a description of several advanced methodologies that can help in designing efficiently long span bridges while reducing the duration of the design process, assessing the required safety and decreasing construction cost would be described.

\section{Risk analysis with regard to wind speed}

\subsection{Definition of flutter wind speed}

One important item to be defined for a long span bridge is the wind speed the structure should withstand before starting flutter instability, in other words, the so called flutter speed.

To define such wind speed the usual procedure is to carry out extensive studies about wind properties at the bridge site aimed to store massive amount of wind data as flow orientation, daily or monthly maximum velocity. Information on these properties is necessary because wind speed is not a fixed value, on the contrary, is a totally random variable that needs to be characterized. The final aim of these studies is to define:

a) An expression for the probability density function of the maximum wind speed and the correspondent cumulative distribution function.

b) An expression for the return period $\mathrm{T}$ of each value of wind speed.

An example that identifies the application of that methodology is the ongoing project of the bridge over the Messina Strait in Italy, a suspension bridge that with a main span of $3300 \mathrm{~m}$ will be the world record. Some graphical information of that construction showing the bridge location and some technical data appears in Figure 1.

To identify the properties of the wind flow at the bridge site, a meticulous study was worked out a few years ago [2].

According to the data obtained the probability density function of the maximum wind speed turned out to be a Gumbel distribution defined by

$$
F_{x_{v}}\left(x_{v}\right)=\exp \left[-\exp \left[-\alpha\left[x_{v}-u\right]\right]\right]
$$


where $x_{v}$ is the wind speed and $\alpha=0.271$ and $u=26.393 \mathrm{~m} / \mathrm{s}$. A graphical representation of such function appears in Fig 2a) and also the corresponding curve relating wind speed and return period $T$ is shown in Fig. 2b).

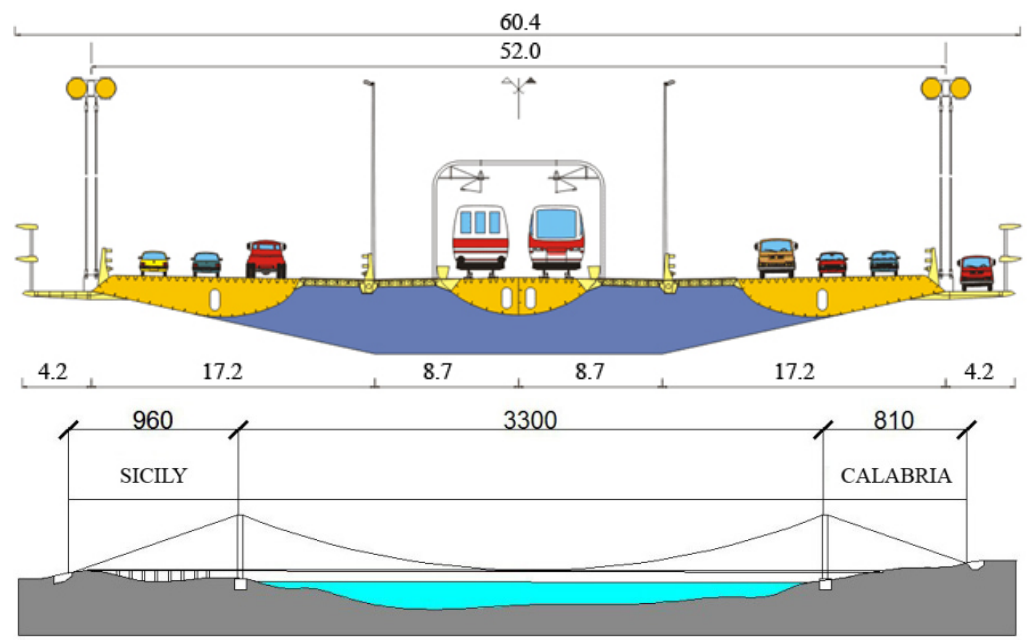

Figure 1: $\quad$ Some details of the future Messina strait bridge.

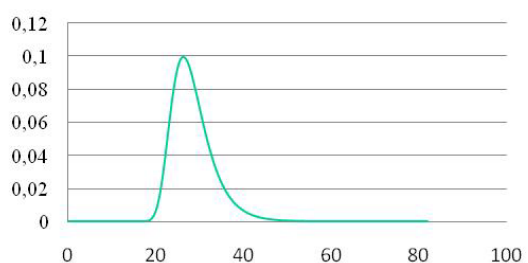

a) Probability density function

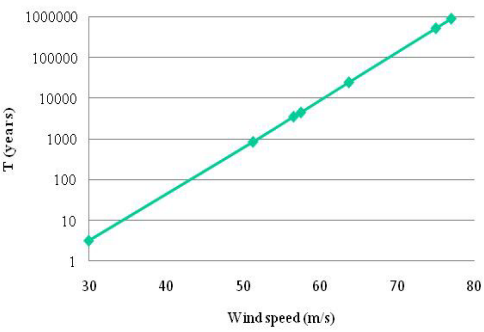

b) Return period vs. wind speed.

Figure 2: $\quad$ Wind speed at the Messina strait site.

In the requirement list for the competition of the Messina bridge a condition existed imposing a value of the flutter speed of $V=75 \mathrm{~m} / \mathrm{s}$. Looking at Figure 2.b it can be observed that the return period of $T=1000$ years correspond to a wind speed of $V=50 \mathrm{~m} / \mathrm{s}$. A return period of a millennium looks like a sensible amount of time, so that decision can be considered adequate, but then a safety coefficient of 1.5 was adopted that led to the mentioned value of $V=75 \mathrm{~m} / \mathrm{s}$.

Once fixed this value the problem of assessing bridge safety regarding to flutter consists on evaluating flutter speed using for instance, the Scanlan formulation and comparing the resulting $V_{f}$ with the mentioned limit value. If $V_{f}>75 \mathrm{~m} / \mathrm{s}$ the design can be accepted and this is the procedure commonly used. 
This situation does not mean that the bridge is completely safe. Given the random nature of wind speed there is always a probability of failure $P_{f}$ that can be evaluated using the cumulative distribution function. For instance, for $75 \mathrm{~m} / \mathrm{s}$ such value is $P_{f}=8 \cdot 10^{-28}$ as shown in Figure $3 \mathrm{a}$ ). This is an extremely small value that actually means that the bridge is, in fact, very much protected under flutter problem, probably too safe indeed. This is because the idea of applying the safety coefficient of 1.5 to the wind speed with a return period of $T=1000$ years turns out a wind speed with a return period of $T=500000$ years as indicated in Figure $3 b$ ) that is too extreme and makes little sense. This result shows that application of safety coefficients to random loads may not be an appropriate approach.

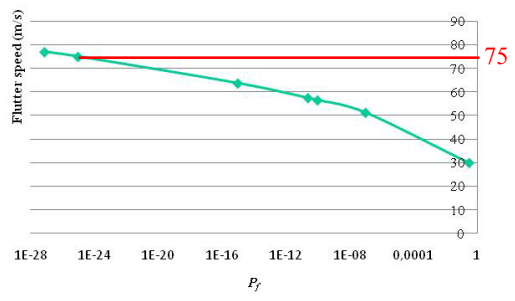

a) Probability of failure

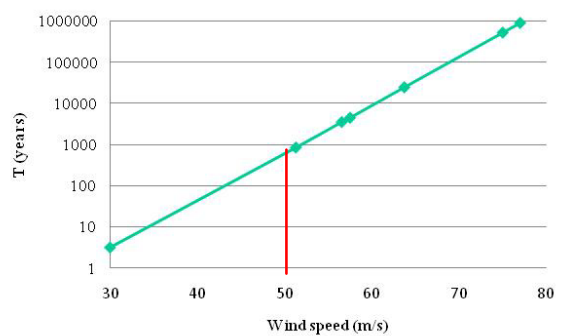

b) Return period

Figure 3: $\quad$ Bridge safety and return period of wind speed of $V=75 \mathrm{~m} / \mathrm{s}$.

More efficient approaches could be the following:

1) Assume a return period $T$ for wind speed and avoid the use of safety coefficients. For instance accepting $T=4500$ years that is similar to the age of the Egyptian Giza pyramids means a wind speed of $V=57.5 \mathrm{~m} / \mathrm{s}$ and a bridge able to cope with such velocity will have a probability of failure of $P_{f}=2.5 \cdot 10^{-11}$ which is a very acceptable value in structural engineering. Therefore in practical terms, no real increment of danger has been introduced by decreasing the value of flutter speed required to the bridge. Of course designing a bridge with a requirement for flutter speed of $V_{f}=57.5 \mathrm{~m} / \mathrm{s}$ will be much inexpensive that for $V_{f}=75 \mathrm{~m} / \mathrm{s}$ thus a vast amount of savings could be achieved. Figure 4 shows graphically the mentioned results.

2) Take in account that not only wind speed is a random variable but also some experimental data, as the values of the flutter derivatives obtained in the segmental bridge test are uncertain and can be described as random variables. If this fact is accepted the next step is to carry out an evaluation of bridge safety using reliability analysis techniques. Several problems in car and aerospace engineering are tackled out in that way that means to define probability density functions for each random variable in consideration as apply reliability methods as FORM, FOSM or SORM to solve the problem. Some work has been already done in the past with this approach $[3,4]$. 


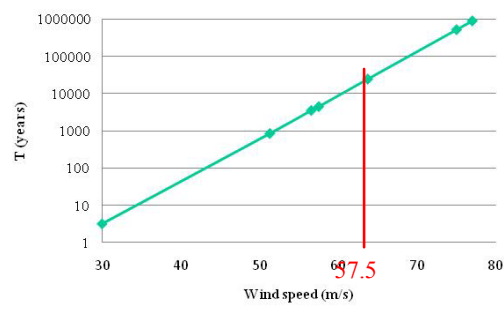

a) Return period

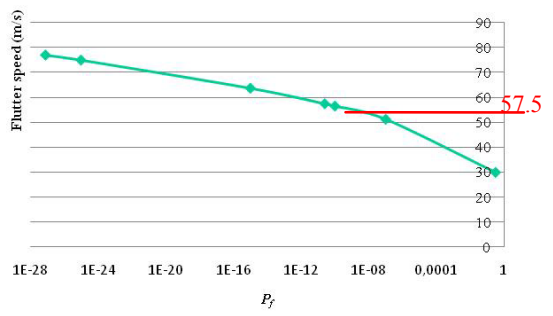

b) Probability of failure

Figure 4: $\quad$ Return period and probability of failure for $V_{f}=57.5 \mathrm{~m} / \mathrm{s}$.

\section{Fully computational evaluation of flutter speed}

Evaluation of bridge safety under flutter started some decades ago as a complete experimental technique by carrying out test of reduced models of the full bridge in boundary layer wind tunnels. Such procedure has several advantages because provides information of many kinds but also the inconvenience of the expensive cost to set up the facility and the money and time required for preparing the model of the full bridge and conduct the test in the laboratory.

Because of that a new formulation has consolidated since some time ago consisting on a combined use of experimental measurements and computational analysis. It is based upon a procedure formulated by Scanlan that indicates that flutter appears because aeroelastic self - induced loads are created by laminar wind flow over a vibrating bridge. Such aeroelastic forces rely on a set of eighteen functions called flutter derivatives than can be obtained in a test where a reduced model of a segment of bridge deck vibrates under wind flow. Figure 5 shows the set of aeroelastic forces and Figure 6 a picture of the reduced model of a segment of the Messina strait bridge deck.

Aeroelastic forces depend of bridge displacements and their first derivative with regards to time as described in the following expression.

$$
\mathbf{f}_{a}=\left\{\begin{array}{l}
F_{y} \\
F_{z} \\
M_{x}
\end{array}\right\}=\frac{1}{2} \rho V K B \cdot\left(\begin{array}{ccc}
P_{1}^{*} & -P_{5}^{*} & -B P_{2}^{*} \\
-H_{5}^{*} & H_{1}^{*} & B H_{2}^{*} \\
-B A_{5}^{*} & B A_{1}^{*} & B^{2} A_{2}^{*}
\end{array}\right)\left\{\begin{array}{c}
\dot{v} \\
\dot{w} \\
\dot{\varphi}_{x}
\end{array}\right\}+\frac{1}{2} \rho V^{2} K^{2} \cdot\left(\begin{array}{ccc}
P_{4}^{*} & -P_{6}^{*} & -B P_{3}^{*} \\
-H_{6}^{*} & H_{4}^{*} & B H_{3}^{*} \\
-B A_{6}^{*} & B A_{4}^{*} & B^{2} A_{3}^{*}
\end{array}\right)\left\{\begin{array}{c}
v \\
w \\
\varphi_{x}
\end{array}\right\}
$$

Where $\rho$ is air density, $V$ is wind speed, $B$ is bridge width, $K$ is the reduced frequency $K=B \omega / V, \omega$ is the vibration frequency and $A_{i}^{*}, H_{i}^{*}, P_{i}^{*} \quad(i=1, \ldots, 6)$ are the flutter derivatives. After obtaining them evaluation of flutter speed is done by establishing the dynamic equilibrium of the structural model under such set of loads.

$$
\mathbf{M} \ddot{\mathbf{u}}+\mathbf{C} \dot{\mathbf{u}}+\mathbf{K u}=\mathbf{f}_{a}=\mathbf{C}_{a} \dot{\mathbf{u}}+\mathbf{K}_{a} \mathbf{u}
$$

Such formulation leads to an eigenvalue problem that finally provides the value of the wind speed producing incipient flutter of the bridge. 


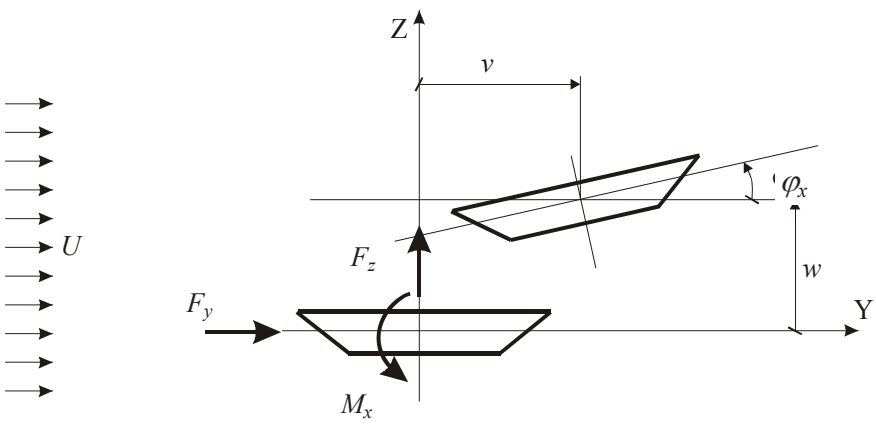

Figure 5: Aeroelastic forces.

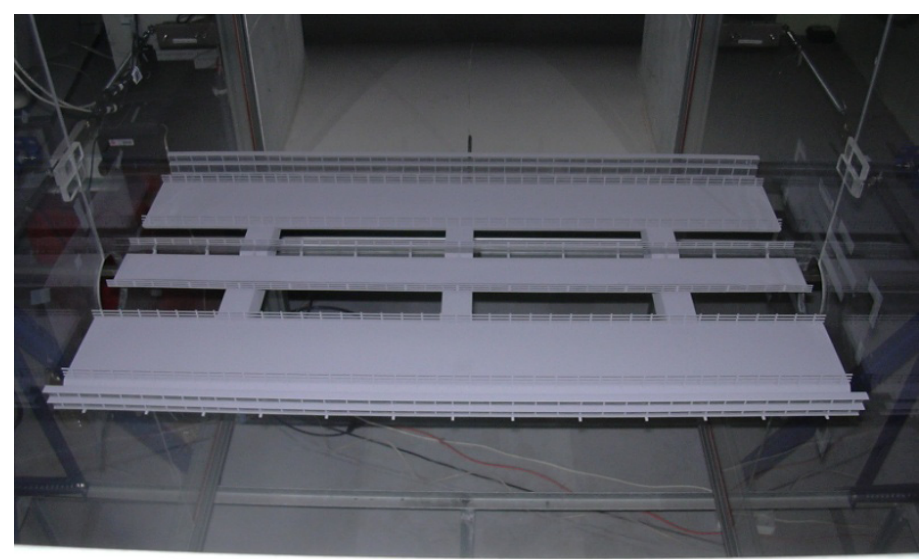

Figure 6: $\quad$ Reduced model of the Messina strait bridge deck.

It is well known that the final shape of a bridge deck is the output of a series of modifications that take place along the design process. Therefore each major change in deck configuration should be checked against flutter behaviour. This can be prohibitive in terms of test in boundary layer wind tunnels and also evaluations of the flutter derivatives for each intermediate deck design can be cumbersome and costly.

Hence remains the challenge of using exclusively computational procedures for evaluating the behaviour of a bridge under laminar flow, in other words the fully computational evaluation of flutter speed.

This could be done by using computational fluid dynamic (CFD) tools for identifying the set of flutter derivatives and thus eliminating the test of the reduced model of the deck segment. Afterwards the eigenvalue problem of expression (3) could be worked out.

Some effort in this line has been developed so far for several researchers, such as Walther and Larsen [5, 6], Xiang and Ge [7], Fransos and Bruno [8, 9], Sun et al. [10] or Bai et al. [11]. Current achievements show that a subset of the 
eighteen flutter derivatives can be obtained with some degree of accuracy when compared to previous results from test of segments of bridge deck models. But the level of coincidence is not high enough and the degree of approximation is significantly case dependant. Therefore it cannot be said that this technique can replace nowadays the test of segmental desk model for real engineering problems.

An alternative that can produce quite appropriate results and may be useful during the design process, when several changes take place, consists on accepting an approximation of the values of flutter derivatives by using the expressions of the aerodynamic coefficients $C_{L}, C_{M}, C_{D}$ and their derivatives with regards to the attack angle of flow $\alpha$.

Such coefficients can be obtained with accuracy using CFD software. This is done by creating a mesh of a domain that represents the wind tunnel and solving the Navier-Stokes equations for a rigid body immersed in a wind flow. Figure 7 shows details of domain discretizations for several configurations of bridge deck.

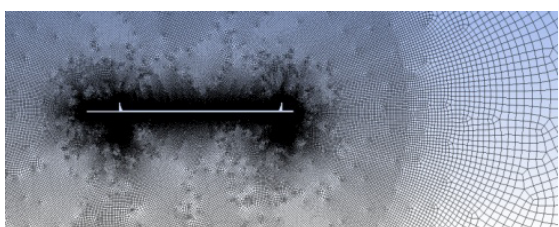

a) Open section deck

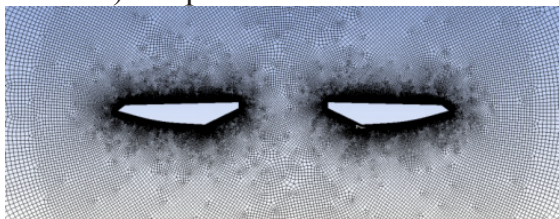

c) Double box deck

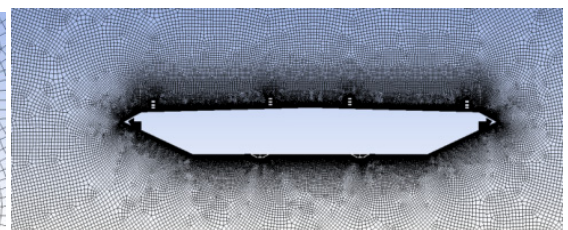

b) Single box deck

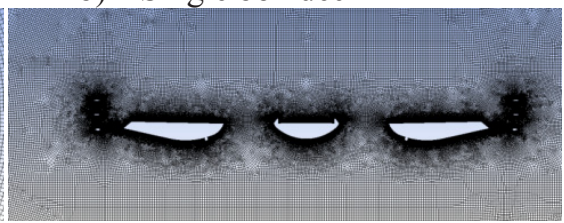

d) Three box deck

Figure 7: Details of CFD domain discretization for different bridge decks.

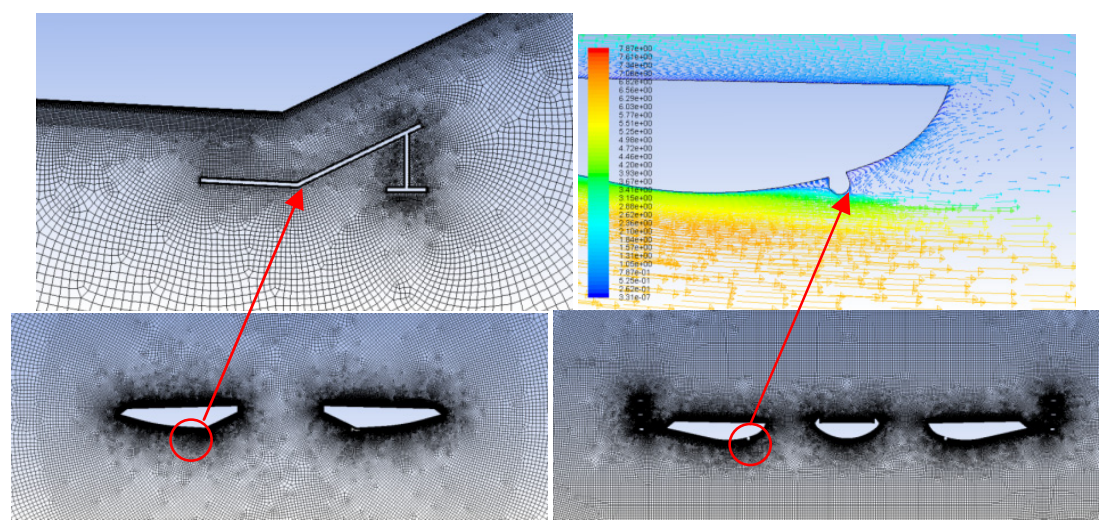

a) Maintenance rail

b) Guide vane

Figure 8: Details of small dimensions in CFD deck models. 
In Figure 9 the geometry of a bridge deck and graphical representation of $\mathrm{C}_{\mathrm{L}}$, $\mathrm{C}_{\mathrm{M}}, \mathrm{C}_{\mathrm{D}}$ with regards to the attack angle $\alpha$ over shown.

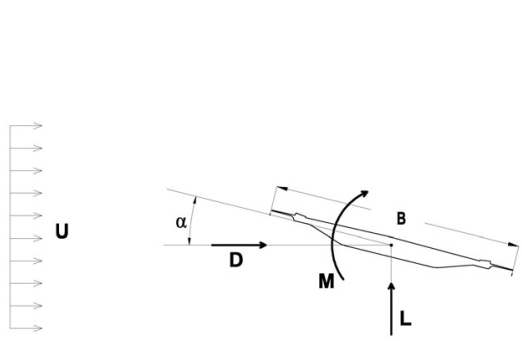

a) Bridge deck

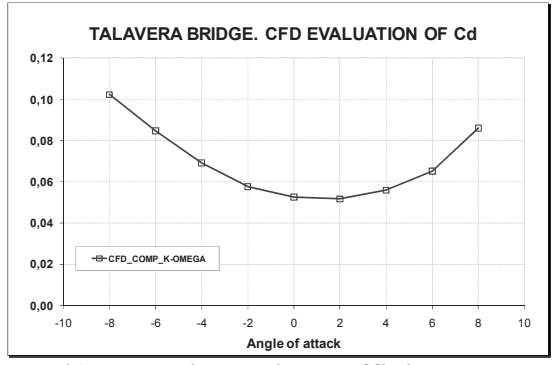

b) Aerodynamic coefficient $C_{D}$

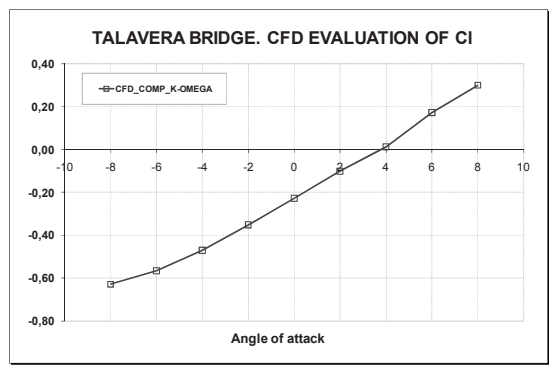

c) Aerodynamic coefficient $\mathrm{C}_{\mathrm{L}}$

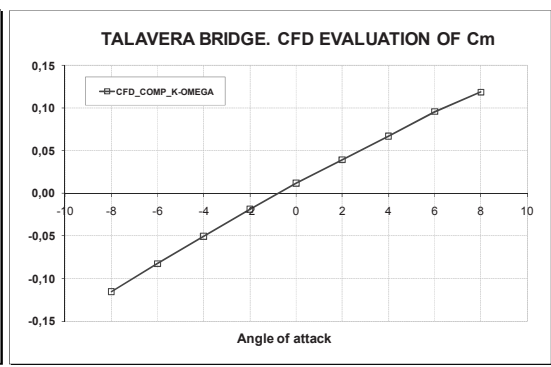

d) Aerodynamic coefficient $\mathrm{C}_{\mathrm{M}}$

Figure 9: $\quad$ Bridge deck and aerodynamic coefficients.

The quasi-steady theory allows us to formulate some flutter derivatives from the values of the aerodynamic coefficients and their derivatives.

$$
\begin{array}{llll}
P_{1}^{*}=-\frac{2 C_{D O}}{K} & P_{2}^{*}=-\frac{\hat{C}_{D O}-C_{L O}}{K} & P_{3}^{*}=\frac{\hat{C}_{D O}}{K^{2}} & P_{5}^{*}=\frac{\hat{C}_{D O}-C_{L O}}{K} \\
H_{1}^{*}=-\frac{\hat{C}_{L O}+C_{D O}}{K} & H_{2}^{*}=\frac{\hat{C}_{L O}+C_{D O}}{K} & H_{3}^{*}=-\frac{\hat{C}_{L O}}{K^{2}} & H_{5}^{*}=\frac{2 C_{L O}}{K} \\
A_{1}^{*}=\frac{\hat{C}_{M O}}{K} & A_{2}^{*}=-\frac{\hat{C}_{M O}}{K} & A_{3}^{*}=\frac{\hat{C}_{M O}}{K^{2}} & A_{5}^{*}=-\frac{2 C_{M O}}{K}
\end{array}
$$

where $C_{D O}, C_{L O}, C_{M O}$, represents the value of the aerodynamic coefficients and $\hat{C}_{D O}, \hat{C}_{M O}, \hat{C}_{L O}$, their derivatives with regards to the attack angle $\alpha$, all of them calculated for horizontal wind flow, namely $\alpha=0$. The remaining flutter derivatives are considered null and with all of them the next step is going to the dynamic equilibrium presented in expression (3) that finally provides the flutter speed. Although this procedure is quite practical it is clearly a simplification and, 
as mentioned before, the real challenge is to produce computationally accurate values of the complete set of flutter derivatives. A task that remains so far unachieved.

\section{Aeroelastic shape optimization of bridge decks}

Optimum design is a scientific discipline that started 51 years ago with the seminal paper of Schmit [12]. Half a century later is a well established research field with many practical applications in several classes of engineering as car or aerospace [13]. In essence it supposes the replacement of the common engineering approach based on introducing changes in the design by using trial and error method for a more rigorous procedure were changes are made automatically by an algorithm that finally provides the best solution for the conditions included in the problem. Figure 10 shows the flow chart of both approaches.

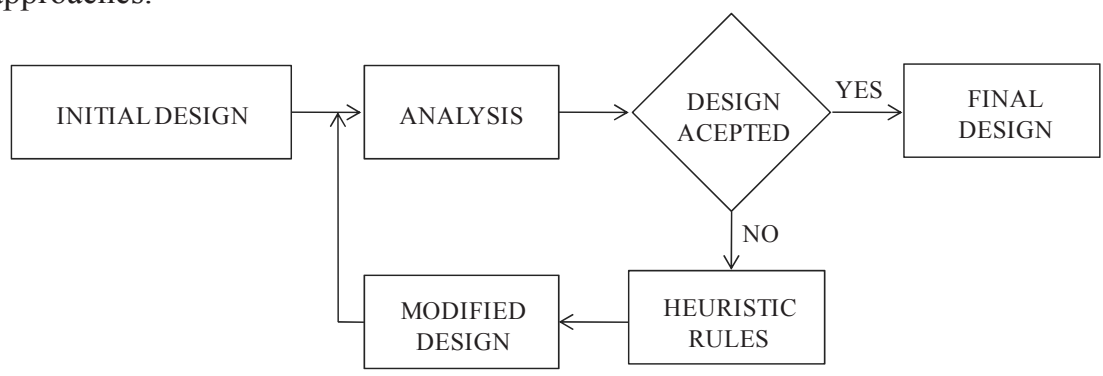

a) Conventional procedure

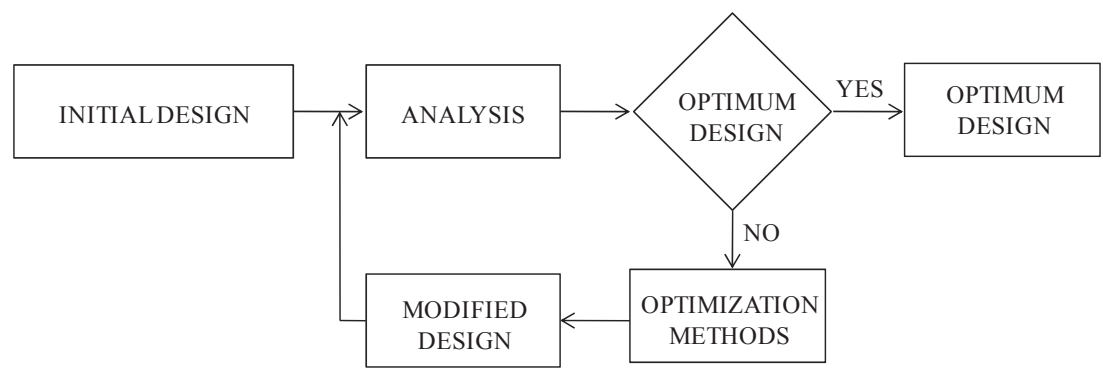

b) Optimization procedure

Figure 10: Approaches to engineering design.

In long span bridges two main considerations lead to the design of a bridge deck: One is the necessary stiffness needed to reduce the value of displacements of the span to the levels required for the traffic, mainly cars or trains. The second is the convenience of good aeroelastic behaviour of the bridge. The problem is that both considerations work in divergent ways. Bridge stiffness leads to decks 
with important depth that needs less amount of material to deliver enough bending inertia. On the contrary, an efficient aeroelastic performance is linked to very slender decks with short depth. Figure 11 shows the real deck of a cable stayed bridge recently designed in Spain and an ideal deck for bending purposes, both with the same width.

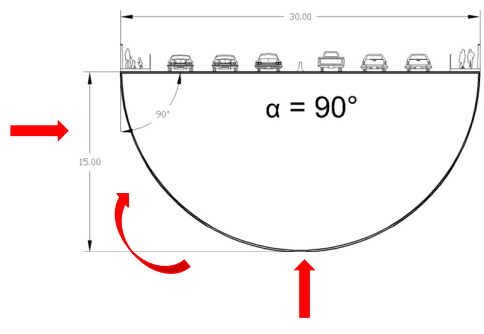

a) Ideal deck for stiffness

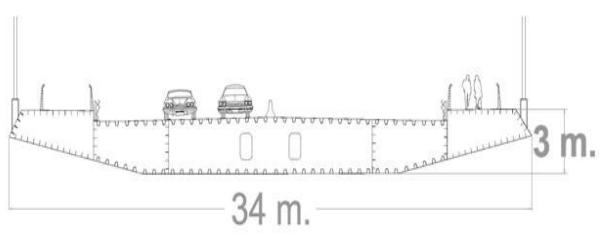

b) Real bridge deck

Figure 11: Ideal and real bridge deck.

During the design of a bridge deck to improve aeroelastic performance means to decrease bridge depth. But, fixing the value of the inertia modulus leads to increase cross sectional area and consequently the amount of material and, therefore, bridge weight. If the value of bending inertia is maintained the evolution of deck for a varying angle $\alpha$ is shown in Figure 12 and the resultant values of the cross section are appears in Table 1 . It can be concluded that shortening the depth of bridge deck implies significant addition of material.
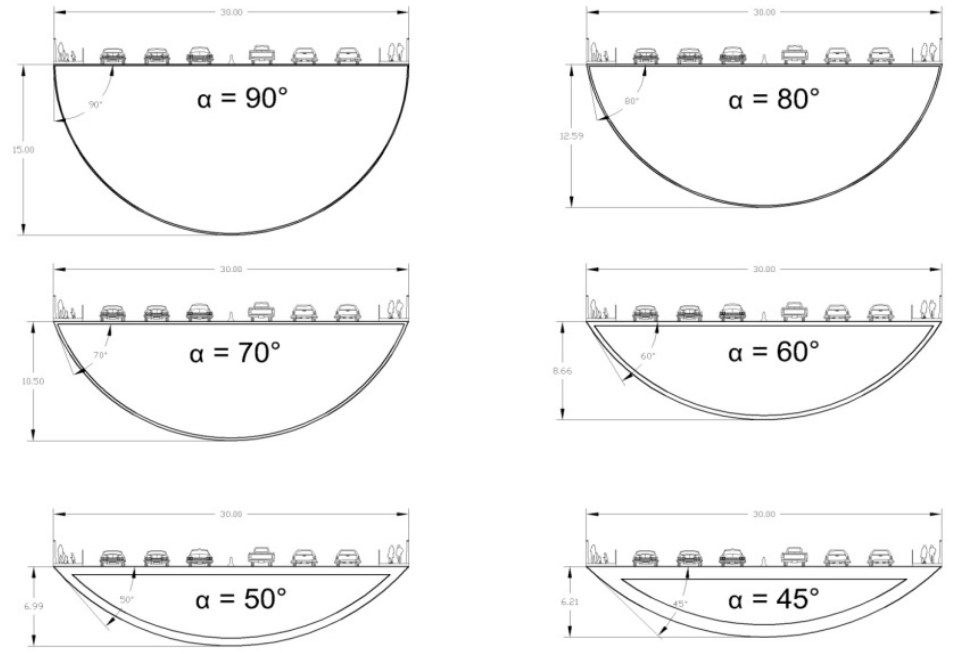

Figure 12: Cross section for different bridge shapes. 
It seems clear that a compromise is drawn in each real design case. Commonly it is done after several trial and errors steps. It is our opinion that substituting this procedure for a more rational process based on optimization methodologies could lead to improved configurations in also short periods of design process and this is a research line that the authors are currently working on [14].

Table 1: Values of cross section area for constant inertia modulus.

\begin{tabular}{|c|c|c|}
\hline Angle $\alpha$ & Depth (H) & Area (A) \\
\hline 90 & 15 & 7.6767 \\
\hline 80 & 12.586 & 11.0805 \\
\hline 70 & 10.5 & 16.3252 \\
\hline 60 & 8.66 & 24.5277 \\
\hline 50 & 6.99 & 42.3306 \\
\hline 45 & 6.213 & 62.5139 \\
\hline
\end{tabular}

\section{Conclusions}

Some conclusions can be outlined from the content of this text:

1) While aeroelastic analysis and design of long span bridges has experienced large improvement in the past decades several challenges remain unsolved.

2) Risk analysis regarding the wind speed required in real bridge projects need to be defined more rationally in order to avoid exaggerated values that lead to unnecessary and excessive economical cost.

3) A lot of effort needs to be done is trying to implement CFD techniques to allow fully computational evaluation of flutter speed in bridges avoiding the nowadays application of experimental techniques.

4) The use of optimization methodologies must be incorporated in the design of expensive constructions as long span bridges. Their implementation will provide similar advantages as those already existing in other engineering fields as car or aerospace.

\section{References}

[1] Hernandez, S. The Rias Altas Link. A challenging crossing. Strait Crossing 2001. J. Krokeborg (ed.) pp. 407-414, Balkema 2001.

[2] Valutatione del vento di progetto. Stretto di Messina, 2004.

[3] Choi, S. K., Grandhi, R. V. and Canfield R.A. Reliability based structural design. Springer, 2007.

[4] Hernandez, S., Baldomir, A., Jurado, J. A. and Nieto, F. Reliability analysis of flutter speed of long span bridges. Application to the Messina bridge. IN-VENTO 2010, XI Convegno Nazionale di Ingegnieria del Vento, July 2010, Spoleto, Italy. 
[5] Walther, J. H., Larsen, A. Two dimensional discrete vortex method for application to bluff body aerodynamics. Journal of Wind Engineering and Industrial Aerodynamics, 67-68, pp. 183-193, 1997.

[6] Larsen, A., Walther, J.H. Discrete vortex simulation of flow around five generic bridge deck sections. Journal of Wind Engineering and Industrial Aerodynamics, 77-78, pp. 591-602, 1998.

[7] Xiang, H., Ge, Y. Refinements on aerodynamic stability analysis of super long-span bridges. Journal of Wind Engineering and Industrial Aerodynamics, 90 (12-15), pp. 1493-1515, 2002

[8] Fransos, D., Bruno, L. Determination of the aeroelastic transfer functions for streamlined bodies by means of a Navier-Stokes solver. Mathematical and Computer Modelling, 43 (5-6), pp. 506-529, 2006

[9] Bruno, L., Fransos, D. Evaluation of Reynolds number effects on flutter derivatives of a flat plate by means of a computational approach. Journal of Fluids and Structures, 24 (7), pp. 1058-1076, 2008.

[10] Sun, D., Owen, J.S., Wright, N.G., Liaw, K. F. Fluid-structure interaction of prismatic line-like structures, using LES and Block-iterative coupling. Journal of Wind Engineering and Industrial Aerodynamics, 96 (6-7), pp. 840-858, 2008.

[11] Bai, Y., Sun, D., Lin, J. Three dimensional numerical simulations of longspan bridge aerodynamics, using block-iterative coupling and DES. Computer and Fluids, 39 (9), pp. 1549-1561, 2010

[12] Schmit, L.A. Structural design by systematic synthesis, second Conference on Electronic Computation, ASCE Pittsburg, Pa. pp. 105-132, 1960.

[13] Hernandez, S., Fontan, A.N. Practical applications of design optimization, WIT Press, 2002.

[14] Jurado, J. A., Hernandez, S., Nieto, F. and Mosquera, A. Bridge aeroelasticity. Sensitivity analysis and optimum design, WIT Press, 2011. 